\title{
Do World Nations Have a Solid Grip to Smash the COVID-19 Pandemic?
}

The era of the coronavirus pandemic has proven to be one of the most consequential and life-turning event in modern human history. Until recently, the human race had to deal with epidemics like Ebola and Swine Flu, which although left a lasting impact on medical sciences and pharmaceutical preparations and forced us to revise our action response plans to coordinate a multi-level functional and coordinated response, the current pandemic has clearly failed all these mechanisms built for such a challenging era. The public health systems have been overwhelmed due to lack of preparation and the failure to recognize the severity of the virus on the part of world governments and international organizations. ${ }^{1}$ A well-coordinated response plan within nations and statistical analysis of the potential of the virus and it's affects by major organizations tasked with researching such potentially hazardous genomes might have provided an early indication of the severity of the virus. When we talk about communication, lack of coordination amongst nations in enforcing lockdowns and improvising nationwide mask mandates right from the beginning are also some of the major reasons why the virus is now well out of control with millions affected across the planet with no end in sight. ${ }^{2}$

Many nations have shattered records with alarmingly high number of cases and mortalities within their borders, with many more continuing to grapple with ever-increasing loss of human life while facing a new wave of fresh infections as we enter the winter season. Meanwhile, some Nations are still behind the regulatory measures needed to contain the spread, with people now openly flouting the rules and regulations they followed in earlier lockdowns imposed by respective governments and authorities in major metropolitans and suburban areas. ${ }^{3}$ The World Health Organization has struggled to get all it's member states on the same page and to follow the listed regulatory guidelines. In the words of John
MacKenzie, a virologist and advisor on the WHO's Emergency Committee, the Leaders at World Health Organization are "very frustrated" with the failure of affected Nations to work in conjunction and in accordance with the safety guidance and response protocols to contain the pandemic. ${ }^{4}$

As we move towards the more disastrous phase of the pandemic, as seen from the rise in cases and deaths in the western hemisphere and continued spread in densely populated nations like India, with the advent of the cold season serving as breeding ground for the virus to spread more valiantly, many are enthused by the positive and convincing results shown by vaccines, with the United Kingdom becoming the first nation to successfully start administering vaccinations to its citizens. ${ }^{5}$ Unfortunately, the distribution and successful administration of the vaccine to billions of people residing in over 200 countries will once again demand rigorous cooperation and coordination amongst countries and states across the globe. And with the current level of coordination recorded and observed amongst nations, there is a high possibility that the failure to learn from the past mistakes of this year can translate towards the vaccine administration process of over seven billion people, spelling possible doom over the entire process and causing unnecessary loss of life by an already out-of-control pandemic. ${ }^{6}$ Such once-in-acentury public health emergency demands nations to cooperate and share data and take effective measures to counter-act and control the spread of the disease, before it becomes uncontrollable. And now, the transport, storage and equitable distribution and administration will require a concerted and coordinated multi-national response from every affected country.

\section{REFERENCES}

1. Gautam A, Dhara B, Mukherjee D, Mukhopadhyay 
D, Roy S, Ganguly SS, et al. A Digital Survey on the Acceptance and Affordability of COVID 19 Vaccine among the People of West Bengal, India- A Survey Based Study. medRxiv 2020.11.13.20229534, https://doi.org/10.1101/2020.11.13.20229534.

2. Ajmera P, Majeed J, Goyal RK, Yadav S, Mukhopadhyay D. Overcoming the Pandemic: Analysing the Ongoing Challenges in the Prevention of COVID-19 in India. Journal of Health Management. 2020;22(4):630-52.

https://doi.org/10.1177/0972063420983076

3. Mehmood Q, Chahal P, Patel P, Upadhyay P, Nawaz A, Mukhopadhyay D, et al. Sex hormones as an emerging weapon to combat COVID-19. OSF Preprints 2021;27.

https://doi.org/10.31219/osf.io/ncwmz

4. Sai LV, Mukhopadhyay D, Dudhraj V, Supriya K, Rajya Lakshmi AV. A Review on Biological and Co-
Morbidity as Potential Factors for COVID 19 Heavy Morbidity and Mortality Among the Elderly and Their Implications on Public Health Scenario in India. International Journal of Pharmacy and Pharmaceutical Sciences 2020;18(02):537-46

5. Ghosh A, Mukhopadhyay D, Patel P, Mukherjee D, Chowdhury J, Samal S. Cholera In The Light Of Covid-19: Coercively Displaced People's Neglected Challenge. World Journal of Pharmaceutical Research 10(6):439-442. https://doi.org/10.20959/wjpr2021620508

6. Mukherjee D, Sarkar P, Ghosh A, Patel P, Chowdhury J, Samal S. Notorious Covid-19 pandemic gives eye opening aid to detect Tuberculosis comorbidity. Medico Research Chronicles 2021;8(2):IV. https://doi.org/10.26838/MEDRECH.2020.8.2.492

Cite this article as:

Monga A. Do World Nations Have a Solid Grip to Smash the COVID-19 Pandemic?. Int Healthc Res J. 2021;5(4):LE1-LE2. https://doi.org/10.26440/IHRJ/0504.07435

\section{AUTHOR AFFILIATIONS:}

U.G. Scholar, School of Pharmaceutical Sciences, Delhi Pharmaceutical Sciences and Research University (DPSRU), Govt. of N.C.T Delhi, New Delhi - 110017 (https://orcid.org/oooo-0003-2077-8429).

e-mail id for correspondence: ankitmonga7167[at]gmail[dot]com 